\title{
Radon: A Messenger and its Health Risks
}

\section{Khan MS*}

Department of Physics, College of Science in Zulfi, Majmaah University, Saudi Arabia

*Corresponding author: Mohamed Shaker Khan, Department of Physics, College of

Science in Zulfi, Majmaah University, Saudi Arabia, Email: mskhan.amu@gmail.com

\section{Editorial}

Volume 2 Issue 1

Received Date: January 21, 2019

Published Date: February 01, 2019

DOI: $10.23880 /$ ijnmrs-16000109

\section{Editorial}

Radon ( $\left.{ }^{222} \mathrm{Rn}\right)$, a noble, invisible, odorless, colorless, tasteless ubiquitous gas, which contribute significantly to the natural background ionizing radiation of about more than $50 \%$. It can be trapped by physical absorption. It is a longest lived isotope in the three naturally occurring isotopes i.e., ${ }^{222} \mathrm{Rn},{ }^{220} \mathrm{Rn} \&{ }^{219} \mathrm{Rn}$. It originates from radioactive decay series of $238 \mathrm{U}$. Firstly, it was discovered by German Physicist Friedrich E. Dorn in year $1898 .{ }^{222} \mathrm{Rn}$, unlike other noble gases because it is a radioactive and toxic gas, but like other noble gases that it is not prone to chemical reaction with other gases. However, it could move freely through pores in soil and cracks in walls; as it is produced from radium $\left({ }^{226} \mathrm{Ra}\right)$ which is found everywhere in the earth's crust. All dwellings contain ${ }^{222} \mathrm{Rn}$ because of its natural presence in varying levels of concentration.

It is both help and hazard. The probability of ${ }^{222} \mathrm{Rn}$ transport within the earth, water and atmosphere makes it a useful tracer for a wide variety of geophysical, geochemical, hydrological and atmospheric purposes. It can move freely so it is able to carry massages. Its applications range from exploration of uranium and hydrocarbon deposits to study gas flow, and their mixing in the atmosphere to recognize fluid transport, and to attempt the prediction of seismic and volcanic events through premonitory changes in the ${ }^{222} \mathrm{Rn}$ concentrations within the earth. Its measurements play a skilful role in the monitoring of human health safety both in the dwellings and mines.
It is by far the most dominant hazardous radionuclide due to its short-lived decay products i.e., Polonium (Po) that are alpha emitters. Exposure to high ${ }^{222} \mathrm{Rn}$ concentrations and its progenies in indoor air leads to increased risk of lung cancer, if it is present at enhanced levels beyond the maximum permissible limit [1]. The World Health Organization (WHO) reported that the radiation dose due to exposure of ${ }^{222} \mathrm{Rn}$ is about 0.025 $\mathrm{mSv} \cdot \mathrm{y}^{-1} / \mathrm{Bq} \cdot \mathrm{m}^{-3}$, which is equivalent to a chance of lung cancer of about $2 \times 10^{-6}$ per Bq. ${ }^{-3}$ per year per person [2]. Lung cancer, it is the disease which is biggest killer of all the cancers. It is the second leading cause of lung cancer after smoking. The WHO recommended the action level of $200 \mathrm{~Bq} \cdot \mathrm{m}^{-3}$ to reduce exposure to ${ }^{222} \mathrm{Rn}$. The action should be taken to reduce indoor ${ }^{222} \mathrm{Rn}$ concentrations when ${ }^{222} \mathrm{Rn}$ exceeds this level. If the ${ }^{222} \mathrm{Rn}$ gas is inhaled, radiation will continue until, it is eventually turned into lead, an inert non-radioactive substance. The alpha, beta and gamma rays will attack the DNA molecule within the cells to form free radical ions, and transformed into an excited molecule, which may lead to the formation of cancers.

\section{References}

1. Khan MS, Zubair M, Verma D, Naqvi AH, Azam A, et al. (2011) The study of indoor radon in the urban dwellings using plastic track detectors. Environ Earth Sci 63(2): 279-282.

2. BEIR VI (1999) Health effects of exposure to radon. US National Research Council Report, National Academy Press, Washington, D.C.

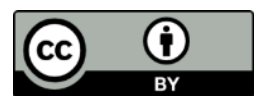

